\title{
Главные риски в исполнении Национальной стратегии Президента
}

\section{Ю.К. Ковальчук, Е.В. Тулин, Е.Г. Пермяков}

Приведены результаты реализации Ассоциацией «Ленплодоовощ» Ленинградской модели восстановления отечественного производства с показателями мирового уровня и лучшими в России, как драйвера динамичного развития экономики, обеспечившего передовые показатели Ленинградской области в России. Приведены главные риски, препятствующие реализации Национальной стратегии Президента и меры по ее безусловному исполнению в условиях ВТО и ТС.

Ключевые слова: Нижегородская модель США, Ленинградская модель РФ, эмбарго, ассоциация «Ленплодоовощ», МВФ, импортозамещение, стратегия Президента. анкции США и ЕС, равно как и введенное Президентом РФ В.В. Путиным в ответ на них эмбарго на поставку импортного продовольствия, выдвинули в число первоочередных задач необходимость импортозамещения, восстановления отечественного производства продуктов. Практическое исполнение задачи импортозамещения с показателями мирового уровня реализовано ассоциацией «Ленплодоовощ» [1]

Национальная стратегия Президента. Начиная с 2005 года, в аграрной политике Президента произошли коренные изменения. Приняты:

- в 2006 году - приоритетный Национальный проект Президента «Развитие АПК»;

- в 2010 году - Доктрина продовольственной безопасности, предусматривающая обеспечить на 80-95\% население качественными отечественными продуктами;

- в 2012 году - закон N121-Ф3 о НКО, как «иностранных агентах», реализующих на коррупционной основе иностранные программы;

• в 2014 году - на санкции США, ЕC введено эмбарго на поставку импортного продовольствия и поставлены задачи импортозамещения;

- в 2018 году - создание на основе НДТ конкурентного отечественного производства.

Статистика подтверждает, что к 1994 году более половины сельхозпредприятий РФ по зарубежным программам сделаны убыточными, (рис. 1) и продолжается их поэтапная ликвидация, как драйвера [2], ос- новы создания конкурентной экономики. Это привело к двойному сокращению производства и потребления продуктов населением и обвальному сокращению населения РФ.

Меры по реализации Национальной стратегии в регионе. По заданию СФ РФ комиссия ОНЧЗ Россельхозакадемии выполнила в 1994 году анализ зарубежных программ и оценила результаты их реализации экспертами МВФ в Нижегородской области [3]. Она установила, что «роспуск колхозов и совхозов», КСХП и «создание крестьянских хозяйств», КФХ ведет к сокращению производства продуктов в два раза, уменьшению производительности труда в 4-15 раз, росту капитальных вложений на обустройство КФХ в 3-10 раз и стоимости продуктов в 2-5 раз. Заключение комиссии доложено в 1995 году на Всероссийском совещании руководителей АПК РФ, растиражировано в СМИ. Правительство В.С. Черномырдина признало необходимость сохранения КСХП и прекратило массовое создание КФХ по НМ США. Из созданных за пятилетие 280,1 тыс. КФХ к 2000 году сохранилось 261,1 тыс. к 2016 году - 174,8 тыс.

В результате роспуска высокодоходных КСХП, формировавших от половины до трети бюджета страны, и создания планово-убыточных КФХ, дотируемых из бюджета, производство продуктов и ВВП РФ сокращены вдвое. А восстановление производства продуктов созданием КФХ в ближайшие десятилетия невозможно, так как потребует на порядок больше капвложений, чем на создание КСХП. Комиссия признала НМ США планово-разрушительной и не рекомендовала ее применение в РФ.

На этой основе, как альтернатива НМ США, под руководством академика Н.Г. Дмитриева, в 1995 году разработана отечественная «Программа восстановления и развития сельского хозяйства, Ленинградская модель» [4]. ЛМ РФ и Госдума РФ приняла Национальные федеральные законы: №53-Ф3 от 02.12.94«О

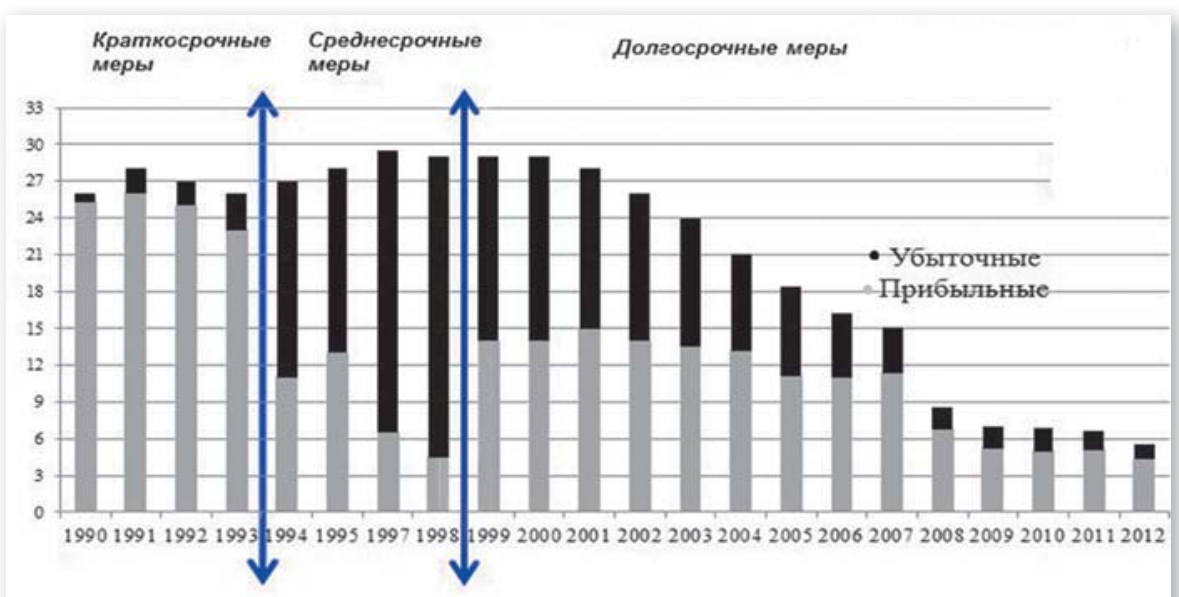

Рис. 1. Динамика рентабельных и убыточных сельхозпредприятий России 
закупках и поставках сельхозпродукции, сырья и продовольствия для государственных нужд»; №100-Ф3 от 14.07 .97 « государственном регулировании агропромышленного производства»; №63-Ф3 от 14.04.98 «О мерах по защите экономических интересов РФ при осуществлении внешней торговли», в которых был обобщен опыт перехода США, ЕС от свободного к регулируемому рынку [5] для унификации правового поля РФ с ведущими членами ВТО.

Результаты реализации Национальной стратегии в регионе. Пилотный проект исполнения первого этапа ЛМ РФ [6] - восстановление и развитие отрасли промышленного овощеводства Ленинградской области - реализован Ассоциацией «Ленплодоовощ», созданной на основе девяти овощемолочных сельхозпредприятий. Кластерный подход, включение в состав Ассоциации научных учреждений, сервисных организаций, Обкома профсоюза работников АПК, их совместная деятельность, обеспечили устойчивый рост производства.

Кластер «Ленплодоовощ», обеспечивая импортозамещение, уже к 2016 году производил в Ленинградской области 90\% овощей, более половины картофеля и пятую часть молока. Урожайность овощей увеличена от 15,4 т/га в 1993 году до 55,6 т/га в 2015 году, при 21,8 т/га в РФ, 38 т/га в США, 35 т/га в Германии, урожайность картофеля - до 25,4 т/га, при 15 т/га в РФ. Продуктивность коров достигла 7680 кг, при 4841 кг в среднем по РФ. Главными факторами четырехкратного роста урожайности овощей, при сокращении в три раза применения минеральных удобрений и производстве экологически безопасных «органических» продуктов, стали Ленинградская модель коллективных крупнотоварных сельхозпредприятий, КСХП, биологическая система земледелия, наукоемкие технологии [1]

Ленинградская область - не лучшее место для с.-х. производства в России. Это ярко выраженная зона рискованного земледелия. Однако официальная статистика утверждает, что область имеет лучшие показатели в России по молочной продуктивности коров и производству молока в сельхозпредприятиях, производству яиц и мяса птицы, урожайности картофеля, овощей, кормовых культур. «Ленплодоовощ» в агроклиматических и рентных условиях, вдвое худших, чем в ЮФО и ПФО, получил в 2-3 раза более высокую урожайность овощей. Таким образом, реально получены по- казатели мирового уровня и лучшие в России, фантастические для современных условий, превысившие в 2-4 раза показатели 1990-1993 годов.

Губернатор Ленинградской области А. Дрозденко выделил главную составляющую передовых показателей Ленобласти в РФ - около 80\% производства в области приходится на крупные сельхозпредприятия, в целом по России - менее половины. Это - официальное признание высокой эффективности ленинградской модели сельхозпроизводства, как драйвера развития экономики, основу которой составляют крупнотоварные коллективные сельхозпредприятия, функционирующие на инновационной основе. Практика «Ленплодоовощ», ЗАО «ПЗ Приневское», восстановившего за два года работу ЗАО «Октябрьское» с показателями мирового уровня, подтверждает, что подобным образом можно восстановить за 2-3 года все сельхозпредприятия России. Результаты реализации Национальной и Зарубежной стратегии переданы Губернаторам СПб и ЛО, Президенту РФ [7].

Результаты реализации НМ США и ЛМ РФ. Сегодня накоплен опыт реализации НМ США Правительствами С-Петербурга (СПб) и Ленинградской области (ЛО). И ЛМ РФ ассоциацией «Ленплодоовощ». Получены статистически достоверные данные, которые действительно подтверждают двойное сокращение производства в девяностых годах прошлого века и наметившуюся стабилизацию в первом десятилетии нынешнего.

Так, в главной отрасли региона, молочном животноводстве, за 90-е годы производство молока по НМ США сокращено вдвое, а стабилизация производства в области в 2000х достигнута в основном за счет его увеличения «Ленплодоовощ» по ЛМ РФ до 100 тыс. т и повышения в 2,2 раза продуктивности коров, до 7680 кг молока на корову. Если отнять из областных показателей показатели производства «Ленплодоовощ», то можно сделать вывод: в области по НМ США продолжается его поэтапная ликвидация, поголовье коров сокращено уже втрое.

Подобная ситуация сложилась и с производством овощей. Реформы 90-х по НМ США привели к двойному сокращению производства овощей. Созданным в 1993 году объединением «Ленплодоовощ», к 2000 году восстановлено дореформенное производство в КСХП с показателями мирового уровня, к 2016 году - увеличено вдвое, до 120 тыс. т, 90\% от областного объема. Но Комитет АПК Правительства ЛО предпринимает меры по расформированию «Ленплодоовощ». Прекращено производство овощей в ЗАО «ПЗ им. Тельмана», ЗАО «Любань», сокращается в СПК «ПЗ Детскосельский» и др. Они выводятся из ассоциации «Ленплодоовощ».

Аналогичная ситуация с производством картофеля. Раньше овощемолочные сельхозпредприятия «Ленплодоовощ» его не производили. За двухтысячные годы увеличили его производство свыше 60 тыс. т. Без учета его производства в «Ленплодоовощ», производство картофеля в сельхозпредприятиях области сокращено с 300 до 30 тыс. т или в 10 раз.

Более драматичная ситуация сложилась в отраслях, в которых «Ленплодоовощ» не принимает участия: практически ликвидировано отечественное промышленное производство говядины, свинины, мяса птицы, яиц.

Официальная

статистика подтверждает:

- «Ленплодововощ», реализуя Национальную стратегию Президента по отечественной программе, восстановил в КСХП промышленное конкурентное производство молока, картофеля, овощей с показателями мирового уровня и ЛМ РФ обеспечила передовые показатели ЛО в РФ;

- реализация Зарубежной стратегии ликвидации высокодоходных КСХП и создания по НМ США убыточных КФХ привела к сокращению производства овощей, картофеля, молока для населения города и области.

А вынужденное потребление населением импортных продуктов, категории для развивающихся стран, в большей части некачественных, опасных для здоровья, привели к резкому росту болезней, смертности, снижению рождаемости.

Практика «Ленплодоовощ», ЗАО «Приневское», убедительно показывает, что отечественное производство в Ленобласти можно восстановить за 2-3 года, как в ЗАО «Октябрьское», в пределах нормативных сроков освоения импортозамещающих и экспортных технологий. Приведем несколько конкретных примеров устранения рисков.

Внутриотраслевая разбалансированность рынка. Для ее устранения ФЗ РФ №53-Ф3 от 2.12.94 «О закупках и поставках сельхозпродукции, сырья и продовольствия для государс- 

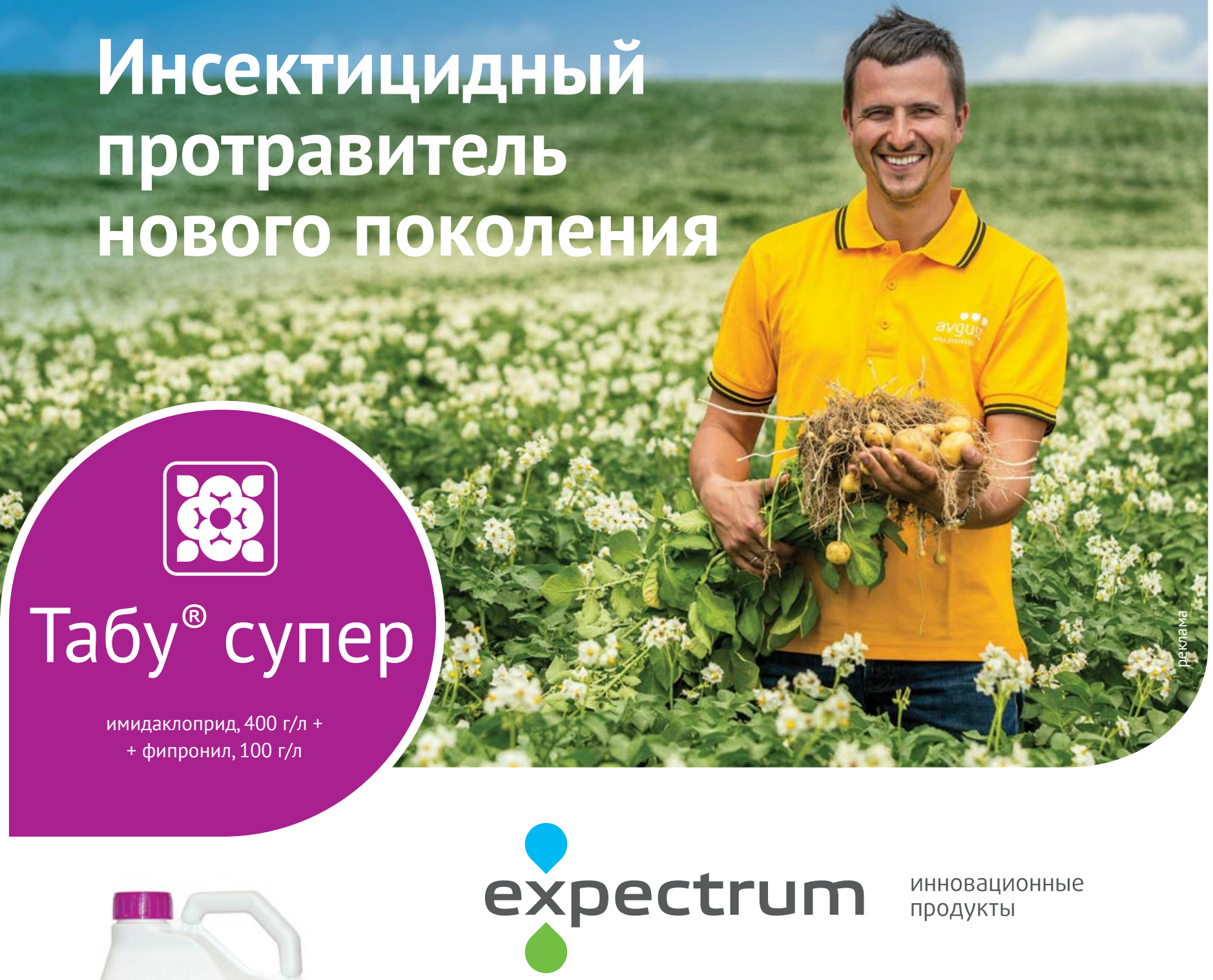

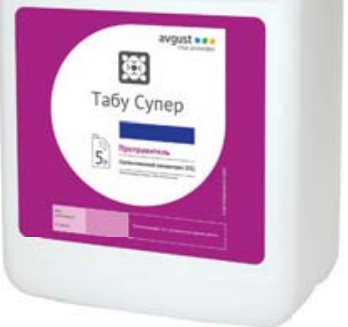

АО Фирма «Август»

Центральный офис в Москве

129515, г. Москва, ул. Цандера, д. 6

Тел.: (495) 787-08-00

Факс: (495) 787-08-20
Инсектицидный протравитель

для защиты картофеля от проволочника, колорадского жука и тлей

Моментально уничтожает проволочника всех возрастов и надежно контролирует наземных вредителей. Сочетает два действующих вещества из разных химических классов. Обеспечивает долговременную и полную защиту от проволочника культур в севооборотах, в которых для посева или посадки используют протравленные им семена или клубни. Эффективен против популяций вредителей, устойчивых к неоникотиноидам и пиретроидам. Не имеет аналогов по эффективности и рентабельности применения. Зарегистрирован также для применения на зерновых культурах, кукурузе, подсолнечнике и сое. 
твенных нужд», предусмотрено, п. 3, ст. 6: «Правительство РФ устанавливает нормативное соотношение между стоимостью закупаемого сырья и стоимостью вырабатываемой из него готовой продукцией, а также предельный размер торговых надбавок к ценам на продукцию, поставляемую в Федеральный фонд, с учетом безубыточной реализации готовой продукции. Правом соответствующего регулирования цен на ...продовольствие, поступающего в региональные фонды, наделяются органы исполнительной власти субъектов РФ».

Почему нужно обязательно исполнять это требование ФЗ РФ? Так, при производстве молока, плодоовощей в технологической цепочке «поле-магазин» затраты труда и ресурсов составляют у сельхозпроизводителей около 70-80\% от общих затрат, у переработчиков (молокозаводов, овощебаз) 12-22\%, в торговле 8\%. Технологическая цепочка в молочной отрасли будет нормально функционировать, если в такой же пропорции, 70, 22, 8\%, пропорционально фактическим затратам, будет распределяться и доход от реализации молока населению между субъектами рынка.

«Нормативное соотношение» это одно из ключевых положений, исполнение которого у ведущих членов ВTO, США, ЕС обеспечивает паритетные внутриотраслевые цены. Суть нарушения ФЗ РФ изложена в письмах Ассоциации «Ленплодоовощ» к Губернатору C-Петербурга. Что «... условиях регулируемого рынка сельхозпроизводители получали от суммы реализованной продукции 75-80\% выручки, а 20-25\% получало оптово-розничное звено, то сейчас, в условиях нерегулируемого рынка сельхозпроизводитель получает 20-25\% от суммы выручки». Т.е., ценовая пирамида перевернута с ног на голову.

Межотраслевая разбалансированность рынка. Ущерб от нее на порядок больше. Для ее устранения ФЗ РФ №53-Ф3, п. 4, ст. 2, предусматривает: «Правительство РФ, органы исполнительной власти субъектов РФ содействуют развитию продовольственных рынков, стабилизации межотраслевых и межрегиональных связей и стоимостных пропорций, обеспечивают поддержание ценового паритета между сельским хозяйством и другими отраслями экономики». Анализ статистических данных дает основание для выводов:

1. При свободном ценообразовании цены растут непрерывно.

Фактически, за пятилетие цены увеличились в тысячи раз.
Фундаментальная экономическая теория объясняет [5]: повышение цен это главный способ получения предпринимателем максимальной прибыли. Добровольно ни один предприниматель цены не снизит.

2. Цены растут разными темпами, нарастает диспаритет цен.

В Ленинградской области, все высокорентабельные (+30\%, в 1990 году) c.-х. предприятия, в результате нарастающегодиспаритетацен и незаконного изъятия почти всех доходов, сделаны на 80\% убыточными. Производство продукции в с.-х. предприятиях сокращено с \$2,5 млрд в 1990 году до \$0,27 млрд в 2000 году, прибыль - с \$0,8 млрд до \$0,12 млрд., инвестиции в основной капитал - с \$0,6 млрд. до \$0,02 млрд. Прямой ущерб в результате неисполнения Ф3 РФ №53-Ф3 превысил \$2 млрд и стремительно нарастает. Ликвидировано в сельском хозяйстве города и области 170 тыс. рабочих мест, вдвое сокращено производство и потребление продуктов, стремительно нарастает демографическая катастрофа. Возникает ключевой вопрос: у кого оказались деньги, незаконно изъятые у предприятий и населения? Ответ на эти вопросы дает официальная статистика, анализ программ США, ЕС.

Экономический инструмент МВФ изъятия доходов у предприятий и населения.

Официальная статистика утверждает [8], что цены возросли за 1991-2001 годы у нефтяных компаний в 33737 раз, на электроэнергию в 23867 раз, промтовары в 8976 раз, продовольствие в 7861 раз, а оплата труда населению выросла только в 3820 раз. Все субъекты рынка, повысив цены больше чем с.-х. предприятия, изъяли из сельского хозяйства «свою» небольшую долю незаконной прибыли. А больше всех и у всех субъектов без исключения изъяли нефтяные компании. Крайними в сформированном МВФ свободным рынком грабежа оказались сельхозпредприятия и население.

Уже большую часть нефтепродуктов РФ якобы продает развитым странам, США, ЕС. Однако деньги, якобы уплаченные за нефтепродукты, остаются в банках США, ЕС. Главный же ущерб - от сформированного МВФ инструмента изъятия доходов у предприятий и населения. Опережающим повышением цен на энергоносители МВФ раскручивает спираль роста цен на все товары и услуги, и нарастающим диспаритетом цен нефтяные ТНК США, ЕС изы- мают практически все доходы у предприятий, сфер жизнеобеспечения, населения, перемещают их в банки США, ЕС, в экономику США, ЕС.

Диспаритет цен за 1991-2001 годы достиг фантастической величины: продовольствие-энергоносители 1:7, зарплата-энергоносители $1: 10$. Недоплата населению, «отложенный спрос населения», достигли астрономической величины, свыше \$3 трлн. Столько же - у предприятий, сфер жизнеобеспечения. Жизненный уровень снижен с шести прожиточных минимумов в 1990 году до 0,3-0,5. Эти примеры - далеко не полная оценка ущерба.

Межгосударственная разбалансированность рынка. Для ее устранения ФЗ РФ №53-Ф3, п. 2, ст. 6, предусмотрено: «Правительство РФ и органы исполнительной власти субъектов РФ... определяет квоты для товаропроизводителей на закупку сельхозпродукции... на предстоящие пять лет с ежегодным уточнением... по гарантированным ценам».

При этом, п. 1, ст. 6 установлен порядок определения гарантированных цен: «Правительство РФ по согласованию с органами исполнительной власти субъектов РФ и представителями общественных объединений, выражающих интересы товаропроизводителей (поставщиков) и потребителей (покупателей) устанавливает... гарантированный уровень закупочных цен, обеспечивающий возмещение материальных затрат и получение дохода товаропроизводителем (поставщиком), достаточного для расширенного воспроизводства». Такой порядок согласования связан с тем, что закупочные цены носят зональный характер и каждый субъект РФ обязан их устанавливать с учетом местных условий, как это принято в ЕС. T.е., закупочная цена у сельхозпроизводителя (поставщика), удовлетворяющая этим требованиям закона, равна полной себестоимости, плюс 15\%, минимальная нормативная рентабельность, на расширенное воспроизводство.

Но вместо перехода к регулируемому рынку, как в это сделали ведущие члены ВТО, США, ЕС и предусмотрено Национальным ФЗ РФ №53-Ф3, МВФ и его исполнители в Правительствах СПб и ЛО по Зарубежному Ф3 РФ, №44-Ф3 ввели демпинговые цены на импорт, коррупционный порядок закупок продовольствия на основе тендеров (конкурсов). Он создает преференции 


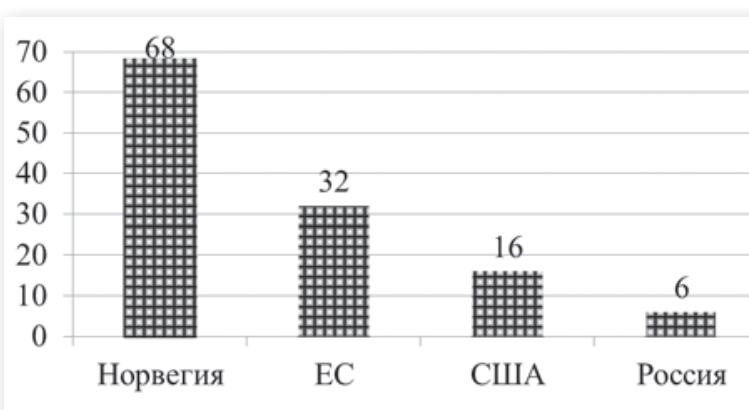

Рис. 2. Уровень господдержки в доходах сельхозпроизводителей, \%

для товаропроизводителей США, ЕС, которые щедро субсидируют из бюджета демпинговые цены.

По данным мировой статистики доля господдержки в доходах сельхозпроизводителей РФ, в три раза меньше, чем в США, в пять раз меньше, чем в ЕС и в десять раз меньше, чем в Финляндии, Швеции, Норвегии (рис. 2). Поэтому импорт товаров на рынок РФ осуществляется, как правило, ниже цен отечественных товаропроизводителей, по демпинговым ценам, вытесняя их с национального рынка. Цена демпинга США, ЕC в Ленинградской области практически полностью ликвидированы отечественные отрасли промышленного свиноводства, птицеводства, выращивания и откорма КРС. Наполовину - молочное производство, промышленное овощеводство, картофелеводство. Прямой ущерб сельхозпредприятиям от спада производства превысил \$10 млрд, что диктует необходимость антидемпингового расследования с целью прекращения демпингового импорта и ввода норм ФЗ РФ, №53-Ф3 для восстановления паритетных межгосударственных ценовых отношений в АПК РФ.

\section{Выводы и предложения}

1. США, ЕС, предложившие «помощь Запада» в «переходе к рынку» по «установленным критериям» МВФ, оказались крайне недобросовестными партнерами. Реализация программ США, ЕС на коррупционной основе, кредиты МВФ, привела к ущербу и людским потерям, превысившим втрое потери от II Мировой войны.

2. Причиной чудовищных потерь стало прежде всего невыполнение академической наукой, РАН, ее НИИ, методологии НИР: системного анализа и оценки реально реализуемых органами власти РФ зарубежных программ. И научное обеспечение РАН, ее НИИ реализации программ США, ЕС в РФ без их предварительной оценки.
3. Анализ и оценка, предусмотренная Методологией НИР, учены м и - аграрника м и Петровской академии программ США, ЕС стала основой разработки и реализации отечественной программы ЛМ РФ, получения передовых показателей Ленинградской области в РФ, коренного изменения аграрной политики Президента, принятия в 2006 году приоритетного Национального проекта Президента «Развитие АПК».

4. Двадцатилетняя практика доказала, что Кластер «Ленплодоовощ», Ленинградская модель коллективных крупнотоварных сельхозпредприятий - это действительно самая эффективная в мире модель хозяйственных формирований, реальная и лучшая в России точка роста для исполнения Национальной стратегии Президента, восстановления отечественного АПК, импортозамещения.

5. Для исполнения Национальной стратегии импортозамещения прежде всего необходимо сделать анализ и оценку реализуемых зарубежных программ во всех отраслях и сферах жизнеобеспечения России

6. Предложить политическим партиям и общественным организациям, их депутатам, на основании экспертных заключений РАН, по факту огромного ущерба и людских потерь, инициировать процедуры прекращения исполнения зарубежных программ, предусмотренные международным законодательством, Конвенциями ООН и отечественным законодательством, ст. 357 УК РФ. Главными аргументами для принятия таких мер является огромный, предумышленно нанесенный ущерб.

Безусловному исполнению Национальной стратегии Президента РФ у нас нет разумной альтернативы.

\section{Библиографический список}

1.Пашинский В.Н., Ковальчук Ю.К. Кластер «Ленплодоовощ»: работа на импортозамещение // Картофель и овощи. 2015. №1. С. 4-8.

2.Ковальчук Ю.К. Драйвер мировой экономики: Ленинградская модель / Raleigh, North Carolina, USA: Open Science Publishing, 2018. 204 p.

3.Ковальчук Ю.К. Нижегородская модель: экспертное заключение // Международный сельскохозяйственный журнал. 1995. № 3. С. 5-8.

4.Программа восстановления и развития сельского хозяйства. Ленинградская модель. Сост. Ковальчук Ю.К. / Под ред. акад. Н.Г.Дмитриева. СПб, 1998. 52 с. 5.Ковальчук Ю.К. Программа «100 дней» Ф.Д. Рузвельта вывода США из Великой Депрессии - опыт для России. Современное экономическое и социальное развитие: проблемы и перспективы / Труды Вольного экономического об- щества России. Вып. 14. СПб.: ООО «СПАН», 2010. С. 47-64. 6.Пашинский В.Н., Ковальчук Ю.К., Летунов С.Б. Ленинградская модель: 20-летняя практика реализации национальной стратегии развития АПК // Научное обозрение: теория и практика. 2016. №3. С. 38-51.

$7.0 б$ исполнении в регионе Федеральных законов по государственному регулированию агропромышленного производства. Открытое письмо экспертов. Сост. Ковальчук Ю.К. СПб: Сударыня, 2004. 35 с.

8.Ковальчук Ю.К. МВФ, США, «семерка» должны отчитаться за результаты реформ энергетики России // Экономическая и философская газета. 2008. №34. С. 39. 9.Ковальчук Ю.К., Пашинский В.Н., Новицкая Т.В. Национальная стратегия реализации Доктрины продовольственной безопасности. Законодательство для исполнения Доктрины продовольственной безопасности в условиях ВТО и ТС: препринт. Ч.4. СПб.: ПАНИ, 2016. 68 с.

\section{Об авторах}

Ковальчук Юзеф Константинович, доктор техн. наук, академик ПАНИ, в.н.с., Федеральное Государственное бюджетное научное учреждение Северо-Западный Научный институт экономики сельского хозяйства. E-mail:kuko@list.ru

Тулин Евгений Васильевич, канд. техн. наук, академик ПАНИ, генеральный директор Ассоциации с. -х. предприятий и обслуживающих организаций «Ленплодоовощ».

E-mail: etulin2807@yandex.ru

Пермяков Евгений Геннадьевич, м.н.с., Федеральное государственное бюджетное научное учреждение «Агрофизический научно-исследовательский институт».

E-mail: lenplod@mail.ru

The main risks in the implementation of the National Strategy of the President J.K. Kovalchuk, DSc, academician PASA, leading research fellow, Federal State Budget Institution Northwest Research Institute of Agricultural Economics. E-mail:kuko@list.ru

E.V. Tulin, PhD, academician PASA,

director general, Association of agricultural companies and service organizations

"Lenplodoovosh".

E-mail: etulin2807@yandex.ru

E.G. Permyakov, junior research

fellow, Federal State Budget Institution

Northwest Research Institute of Agricultural Economics. E-mail: lenplod@mail.ru

Summary. The results of the implementation of the Lenplodoovoshch Association of the Leningrad model of restoring domestic production with world-class indicators and the best in Russia as a driver for the dynamic development of the economy, which provided advanced indicators for the Leningrad region in Russia. The main risks that impede the implementation of the National Strategy of the President and measures for its unconditional implementation in the conditions of the WTO and CU are given.

Keywords: Nizhny Novgorod model of the USA, Leningrad model of the Russian Federation, import substitution, embargo. 